\title{
The AFRL Scholars Program: a STEM-based summer internship initiative
}

Mark Spencer, Imelda Atencio, Julie McCullough, Eunsook Hwang

Mark F. Spencer, Imelda J. Atencio, Julie A. McCullough, Eunsook S. Hwang, "The AFRL Scholars Program: a STEM-based summer internship initiative," Proc. SPIE 9946, Optics Education and Outreach IV, 99460E (27 September 2016); doi: 10.1117/12.2235827

Ev1E Event: SPIE Optical Engineering + Applications, 2016, San Diego, California, United States 


\title{
The AFRL Scholars Program: a STEM-based summer internship initiative
}

\author{
Mark F. Spencer*a,b, Imelda J. Atencio ${ }^{\mathrm{a}}$, Julie A. McCullough ${ }^{\mathrm{c}}$, and Eunsook S. Hwang ${ }^{\mathrm{a}}$ \\ ${ }^{a}$ Air Force Research Laboratory, Directed Energy Directorate, 3550 Aberdeen Ave. SE, KAFB, NM, \\ 87111; ' Air Force Institute of Technology, Department of Engineering Physics, 2950 Hobson Way, \\ WPAFB, OH 45433; 'Universities Space Research Association, AFRL Scholars Program, 3550 \\ Aberdeen Ave. SE, KAFB, NM, 87111
}

\begin{abstract}
The Air Force Research Laboratory (AFRL) Scholars Program offers stipend-paid summer internship opportunities to undergraduate- and graduate-level university students as well as upper-level high school students who are pursuing or plan to pursue degrees in science, technology, engineering, and mathematics (STEM). Internships through the AFRL Scholars Program are currently offered through the Directed Energy, Space Vehicles, and Munitions Directorates of AFRL with locations at Kirtland Air Force Base, New Mexico, Eglin Air Force Base, Florida, and Maui, Hawaii. Throughout their internships, AFRL Scholars gain valuable hands-on experience working with full-time AFRL scientists and engineers on cutting-edge research and technology. Overall, the selected interns are able to contribute to unique, research-based projects which often contain a strong emphasis in optics and photonics. This paper celebrates the continued success of the AFRL Scholars Program and shares a statistical overview of its growth over the past few years. In particular, the analysis focuses on how these STEM-related internships will hopefully meet the needs of an aging AFRL workforce in the years to come. This paper also provides an overview of two optics and photonics related internships at the undergraduate and graduate levels, respectively. Both interns received the Outstanding AFRL Scholar Award in their respective categories and are currently pursuing careers in optics and photonics based on their experiences as AFRL Scholars.
\end{abstract}

Keywords: STEM, AFRL Scholars Program, summer internships, optics and photonics, outreach

\section{INTRODUCTION}

Every year, the Air Force Research Laboratory (AFRL) funds a large number of summer internships for high-school, undergraduate, and graduate students through its AFRL Scholars Program. As shown in Fig. 1, in 2015 the Directed Energy and Space Vehicles Directorates of AFRL at Kirtland Air Force Base (AFB) provided summer internships for over 125 high-school and university students interested in science, technology, engineering, and mathematics (STEM) [1]. A summer internship through the AFRL Scholars Program consists of a primary mentor, a secondary mentor, and a student researcher or 'Scholar'. In general, Scholars must meet the following eligibility requirements:

- A grade point average of at least 3.0 on a 4.0 scale is highly encouraged for all applicants

- Must be a US Citizen, as the program is not open to non-Citizens, Permanent Residents, or Dual Citizens

- Must be enrolled or accepted at an educational institution taking at least half-time academic course load

- Must be in good academic standing

- Must be at least 16 years of age and have a valid driver's license

- Must be available to work fulltime (40 hours per week)

- Must be willing to temporarily relocate to physical work location

- Must be able to take personal responsibility for arranging transportation to and from worksite each day.

- Must be able to pass a background check, potentially resulting in a Secret Security Clearance

*email: mark.spencer.6@us.af.mil; phone: 505-853-1607

Optics Education and Outreach IV, edited by G. Groot Gregory, Proc. of SPIE Vol. 9946, 99460E

(C) 2016 SPIE · CCC code: $0277-786 \mathrm{X} / 16 / \$ 18 \cdot$ doi: $10.1117 / 12.2235827$ 
Based on these eligibility requirements, each Scholar is hand selected by their mentors from a pool of applicants using an online forum. These applicants are categorized by their respective backgrounds (e.g., undergraduate mechanical engineering, graduate physics, etc.). Upon selection, the Scholar works closely with their mentors and other researchers at AFRL to complete a specified project. To compensate them for their time and efforts, the Scholars receive stipends and, in some cases, assistance with housing and travel.

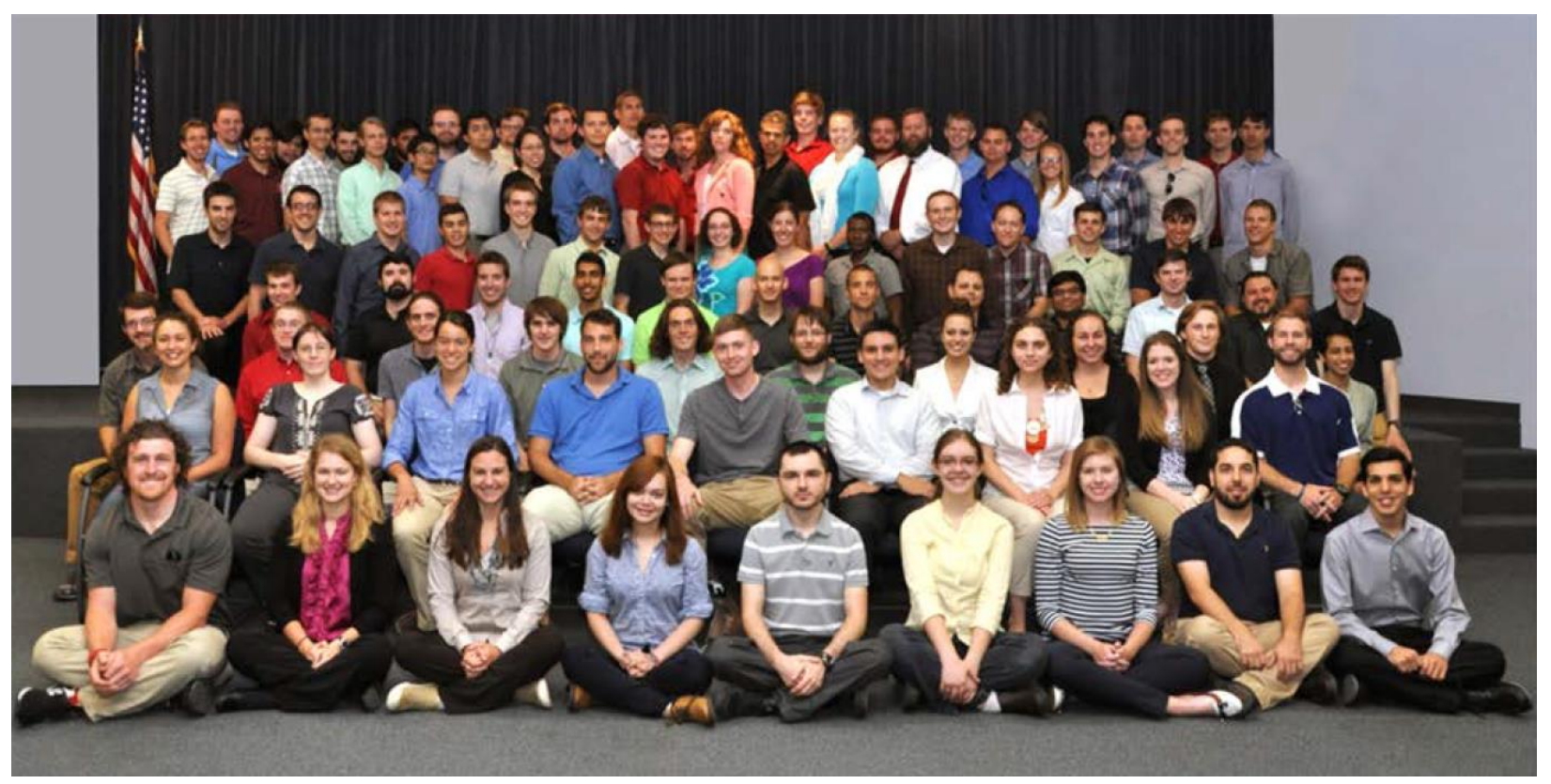

Figure 1. The Air Force Research Laboratory Scholars Program currently offers summer internship opportunities at Kirtland Air Force Base (AFB), New Mexico, Eglin AFB, Florida, and Maui, Hawaii. For example, at Kirtland AFB there are two directorates to potentially work at, the Directed Energy Directorate and the Space Vehicles Directorate. As pictured above, in 2015 both directorates offered over 125 internship positions to Master's- and PhD-seeking graduate students and upperlevel-high-school and college-undergraduate students interested in science, technology, engineering, and mathematics.

The primary objective of the AFRL Scholars Program is to increase student participation in STEM. Long term, the goal is to train the next-generation of scientists and engineers (S\&Es) to help meet the needs of the United States with respect to national defense. To achieve this long-term goal, Scholars work with AFRL S\&Es in a laboratory environment and gain valuable hands-on experience developing cutting-edge technologies which often contain a strong emphasis in optics and photonics. For instance, at Kirtland AFB in the Directed Energy and Space Vehicles Directorates of AFRL, Scholars participate as 1) Directed Energy Scholars, which are graduate students interested in lasers, optics, high-power electromagnetics, and related technologies; 2) Space Scholars, which are graduate students interested in aerospace technologies, cold atom research, satellite image and signal analysis, space weather modeling, and related technologies; and 3) as Phillips Scholars, which are high-school and undergraduate students interested in careers in STEM. These Scholars participate in an organized program of lectures, career workshops, tours of AFRL laboratories, and social activities. The annual program culminates with two poster sessions at which Scholars present their results through posters and/or slides to government leaders and industry experts.

Since its inception in 2001, the AFRL Scholars Program has provided internship opportunities for over 1200 student researchers with positions at Kirtland AFB, New Mexico; at the Air Force Maui Optical and Supercomputing (AMOS) site in Maui, Hawaii; at Eglin AFB, Florida; and at Wright Patterson AFB in Dayton, Ohio. Until 2012, on-site government civilians administered the AFRL Scholars Program. That year, restrictions on government hires led to manpower limitations, which necessitated using an outside contractor to help run the program. Through an agreement with NASA, AFRL was able to use the Universities Space Research Association (USRA) to hire the student interns and conduct much of the administrative work for the program. In 2013, USRA was awarded a multi-year cooperative agreement to execute future scholar programs on behalf of AFRL. USRA's expertise, in partnership with AFRL, provides the AFRL Scholars Program with successful processing of security clearances, stipends, management of inand-out processing, and general facilitation of an outstanding Scholar experience. 
The AFRL Scholars Program website, http://afrlscholars.usra.edu, provides an overview of the program. This website is a valuable resource for Scholars, mentors, and future participants. Specifically, the homepage highlights each of the USRA-supported AFRL sites individually. Updated information and pictures feature the different milestones throughout the program cycle, such as application deadlines, guest speakers, and housing options.

In what follows, this paper provides a statistical overview of the 2015 AFRL Scholars Program at Kirtland AFB in the Directed Energy and Space Vehicles Directorates. In particular, the analysis focuses on how these STEM-related internships will hopefully meet the needs of an aging AFRL workforce in the years to come. This paper also provides an overview of two optics and photonics related internships at the undergraduate and graduate levels, respectively. Both interns received the Outstanding AFRL Scholar Award in their respective categories and are currently pursuing careers in optics and photonics based on their experiences as Scholars.

\section{STATISTICAL OVERVIEW}

This section provides a statistical overview of the 2015 AFRL Scholars Program at Kirtland AFB in the Directed Energy and Space Vehicles Directorates. Specifically, this section covers the following topics: 1) applicant demographics and statistics, 2) participant demographics and statistics, 3) program metrics and outcome assessment, and 4) program annual comparison. Before moving on in the analysis, it is important to note that in $2005,70 \%$ of AFRL employees were over the age of 40 and $29 \%$ were over the age 50. In 2015, 66\% of AFRL employees were over the age of 40 (a $4 \%$ decrease since 2005) and 44\% were over the age of 50 (a 15\% increase since 2015). These percentages really speak to need for the AFRL Scholars Program. Remember that the long-term goal of the AFRL Scholars Program is to train the nextgeneration S\&Es to help meet the needs of the United States with respect to national defense.

\subsection{Applicant demographics and statistics}

For the 2015 AFRL Scholars Program at Kirtland AFB, 1506 applications were initiated and 572 applications were submitted. To complete an application, applicants used an online management system to submit resumes and transcripts and request letters of recommendation. Applicants represented a total of 199 academic institutions from across the United States and Puerto Rico. The data presented in in Fig. 2 outlines the top-level statistics.

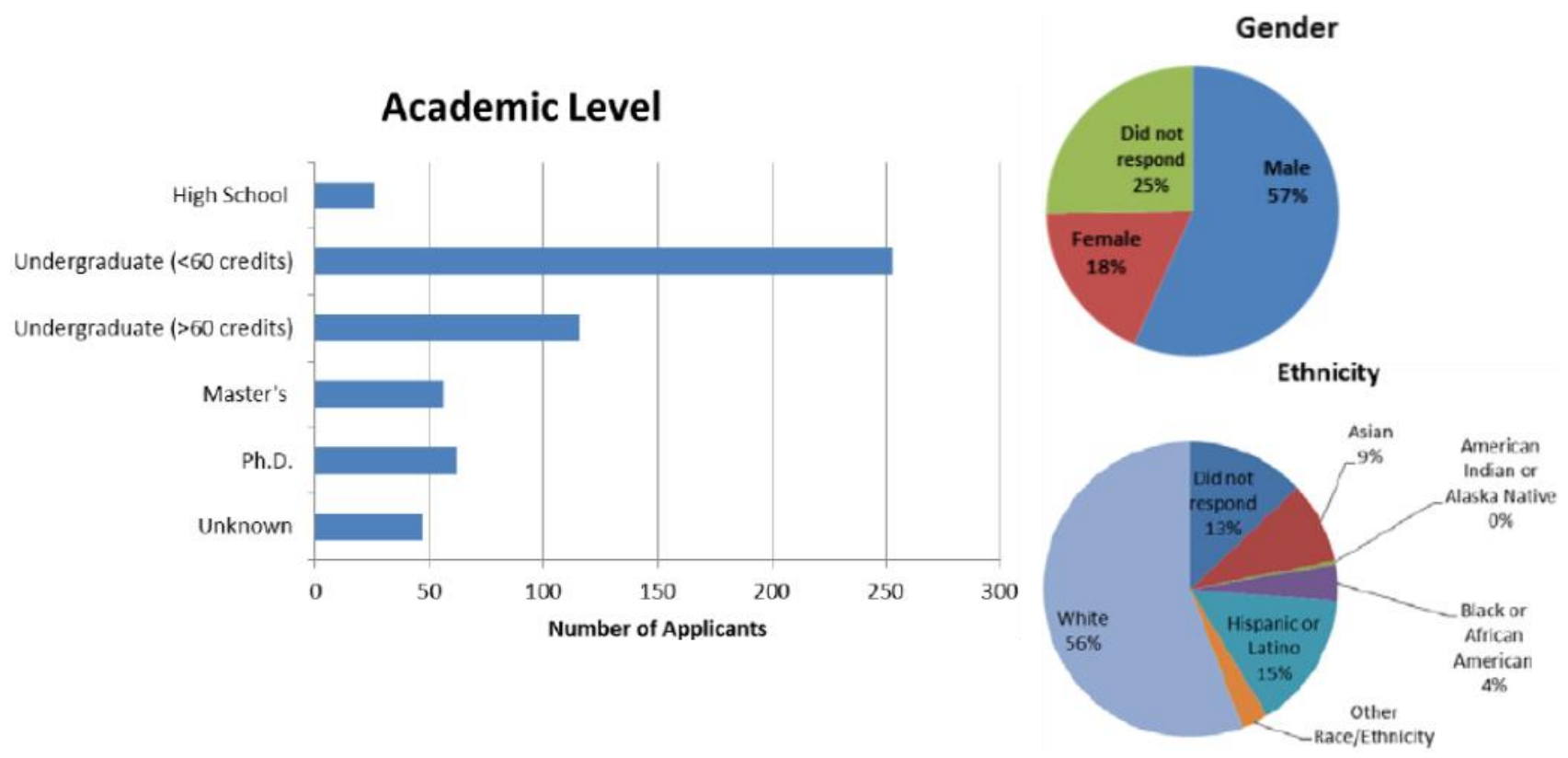

Figure 2. The academic level, gender, and ethnicity of the applicants who submitted applications.

\subsection{Participant demographics and statistics}

Participant demographics and statistics provide insight into the diversity of the AFRL Scholars Program. With that said, returning Scholars represent a significant asset to the AFRL Scholars Program. They bring continuity and consistency to ongoing research and development on specific projects, and they also have the potential to become a viable addition to 
the AFRL workforce at the end of the internship or upon graduation. Scholars who demonstrate exceptional skills and abilities during their internship are often selected to participate in the program for several years. For the 2015 AFRL Scholars Program at Kirtland AFB, returning Scholars represented approximately one-third (46) of the selected scholars. The data presented in in Figs. 3-5 and Tables 1-2 outlines additional top-level statistics.

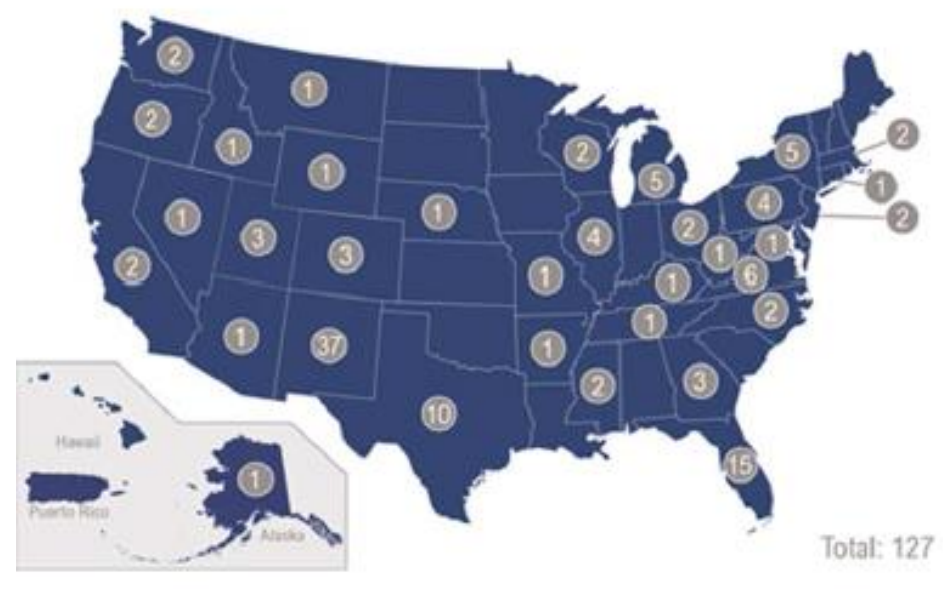

Figure 3. For the 2015 AFRL Scholars Program at Kirtland Air Force Base, 127 Scholars were selected from 34 states within the U.S. The largest number of participants were selected from New Mexico 29\% (37), Florida 12\% (15), and Texas $8 \%(10)$.

\section{Ethnicity}
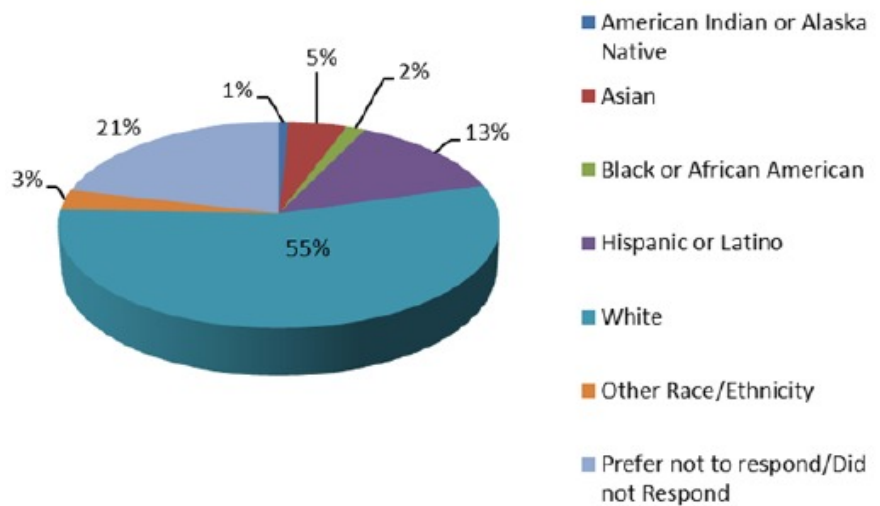

Figure 4. The percentage of minority scholars selected for the AFRL Scholars Program at Kirtland Air Force Base remained consistent from 2014 to 2015. A breakdown of ethnicity and race composition for the program offers an understanding into where recruitment efforts can be strengthened.

\section{Gender}

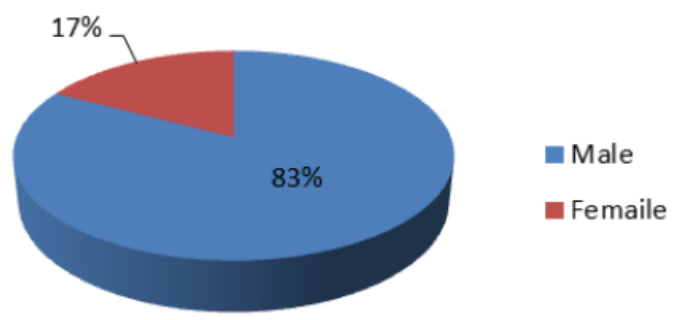

\begin{tabular}{|l|c|c|c|}
\hline \multicolumn{4}{|c|}{ Gender Composition of Selected Students } \\
\hline \multicolumn{4}{|c|}{$2013-2015$} \\
\hline Gender & $\mathbf{2 0 1 3}$ & $\mathbf{2 0 1 4}$ & $\mathbf{2 0 1 5}$ \\
\hline Male & $80 \%$ & $77 \%$ & $83 \%$ \\
\hline Female & $20 \%$ & $23 \%$ & $17 \%$ \\
\hline
\end{tabular}

Figure 5. The breakdown of participants by gender for the 2015 AFRL Scholars Program at Kirtland Air Force Base. Note that the number of males and females who are selected fluctuates annually, as shown in the table. 
Table 1. The academic levels of participants, broken down by program, for the 2015 AFRL Scholars Program at Kirtland Air Force Base.

\begin{tabular}{|c|c|c|c|c|}
\hline Academic Level & $\begin{array}{l}\text { Directed } \\
\text { Energy }\end{array}$ & Phillips & Space & Total \\
\hline High School & -- & 3 & -- & 3 \\
\hline Freshman & -- & 2 & -- & 2 \\
\hline Sophomore & -- & 5 & -- & 5 \\
\hline Junior & -- & 18 & -- & 18 \\
\hline Senior & -- & 28 & -- & 28 \\
\hline Master's & 7 & -- & 23 & 30 \\
\hline Ph.D. & 9 & -- & 32 & 41 \\
\hline
\end{tabular}

Table 2. A representation of academic majors for the students participating in the 2015 AFRL Scholars Program at Kirtland Air Force Base. Scholar majors show specific knowledge and skill sets that Scholars bring to AFRL and are beneficial for targeted recruitment and meeting AFRL's objective to fill the gap in the recruitment workforce. The data establishes the number and diversity of majors that are represented annually.

\begin{tabular}{|l|c|}
\hline \multicolumn{1}{|c|}{ Academic Majors } & Number of Scholars \\
\hline Aerospace/Astronautical Engineering & 32 \\
\hline Architecture & 1 \\
\hline Astrophysics & 1 \\
\hline Biomedical Engineering & 1 \\
\hline Chemistry/Chemical Engineering & 4 \\
\hline Civil Engineering & 1 \\
\hline Computer Engineering/Programming/Science & 6 \\
\hline Electrical Engineering & 20 \\
\hline Geoscience & 3 \\
\hline Interdisciplinary & 1 \\
\hline Materials Science and Engineering & 1 \\
\hline Mathematics & 3 \\
\hline Mechanical Engineering & 19 \\
\hline Nuclear Engineering & 1 \\
\hline Optics & 3 \\
\hline Physics/Engineering Physics & 25 \\
\hline Undecided & 5 \\
\hline
\end{tabular}

\subsection{Program metrics and outcome assessment}

At the end of each summer, scholars and mentors are asked to complete surveys designed to collect valuable feedback on a variety of topics. Results from these surveys are outlined below.

At the completion of the internship, Scholars are surveyed for program impact and satisfaction based on a variety of metrics. For the 2015 AFRL Scholars Program at Kirtland AFB, 98\% of the Scholars responded to the survey. Scholar survey results indicated that $89 \%$ of scholars were influenced to take additional STEM courses. This data offers an indication that the AFRL Scholars Program is meeting AFRL's primary objective of encouraging student interest in STEM education. In addition, survey results indicated the following:

$\cdot 26 \%$ - interested in taking additional science courses 
- $20 \%$ - interested in taking additional technology courses

- $38 \%$ - interested in taking additional engineering courses

- $17 \%$ - interested in taking additional mathematics courses

To evaluate the program's influence on career choices, scholars were asked to assess the impact of their mentor relationship and project experience. Survey results indicated the following:

- $40 \%$ - significant impact of mentors on career decisions

- $75 \%$ - excellent mentor/student relationship

- $57 \%$ - strongly agreed with increased understanding of desired career field

- $64 \%$ - strongly agreed or agreed that their career interests and/or attitudes changed (31\% responded neutral)

Responses from Scholars concerning real-world applications for STEM, the benefits of the research conducted at AFRL, and whether or not they are gaining marketable skills, provide valuable insight into their perception of what they learn while at AFRL. Survey results indicated that $73 \%$ of Scholars "strongly agreed" that they learned real-world, hands-on, technical applications of STEM, and 63\% of scholars "strongly agreed" that the research conducted at the AFRL had significant benefits, representing an $8 \%$ increase over 2014 participants.

Understanding the benefits of the research conducted at AFRL could play a key role in determining future career paths for Scholars. The AFRL experience and skills gained during the internship are highly valued by employers because Scholars demonstrate an aptitude for learning and the ability to apply acquired knowledge. The AFRL Scholars Program at Kirtland AFB offers Scholars the opportunity to gain first-hand, practical experience and skills in their desired career field. This experience and these skills are highly valued by employers because Scholars demonstrate an aptitude for learning and the ability to apply acquired knowledge. Of the responding Scholars, $72 \%$ "strongly agreed" that they gained valuable skills during their internship and $66 \%$ rated their project as "excellent."

At the completion of the internship, mentors are also surveyed for internship outcome and satisfaction on a variety of metrics. For the 2015 AFRL Scholars Program at Kirtland AFB, 88\% of the mentors responded to the survey. Mentors had the opportunity to give an overall rating to their Scholars, including performance suitability to assigned projects, which resulted in a 95\% performance rating of "very good" and "excellent."

A new survey was added for 2015 to gather mentor feedback on program elements and administration and generated a notable $76 \%$ response rate. The feedback included topics such as project submission, selection and ranking of Scholars, as well as communication, instruction, and overall assistance by program administration. Mentors gave an overall rating of $94 \%$ or higher for program administration and $65 \%$ of mentors stated that they would consider mentoring again or recommend mentoring to others.

\subsection{Program annual comparison}

The data presented in Table 3 and Table 4 summarize the top-level statistics for applicant data and participant data, respectively. This data celebrates the continued success of the AFRL Scholars Program at Kirtland AFB and shares a statistical overview of its growth over the past few years.

Table 3. Summary of applicant data over that past few years for the AFRL Scholars Program at Kirtland Air Force Base.

\begin{tabular}{|l|c|c|c|}
\hline & 2013 & 2014 & 2015 \\
\hline Applicants & N/A & 1365 & 1506 \\
\hline Submitted Applications & N/A & 491 & 572 \\
\hline Academic Institutions Represented & N/A & 172 & 199 \\
\hline States Represented & N/A & 42 & 47 \\
\hline
\end{tabular}




\begin{tabular}{|c|c|c|c|}
\hline Academic Level & 2013 & 2014 & 2015 \\
\hline High School & N/A & 43 & 26 \\
\hline Undergraduate (<60 credits) & $\mathrm{N} / \mathrm{A}$ & 204 & 253 \\
\hline Undergraduate (>60 credits) & N/A & 245 & 116 \\
\hline Master's & N/A & 62 & 56 \\
\hline Ph.D. & N/A & 27 & 62 \\
\hline Unknown & N/A & $\mathrm{n} / \mathrm{a}$ & 47 \\
\hline Gender & 2013 & 2014 & 2015 \\
\hline Male & N/A & 320 & 316 \\
\hline Female & $\mathrm{N} / \mathrm{A}$ & 84 & 103 \\
\hline Prefer not to respond & N/A & 78 & 14 \\
\hline Ethnicity & 2013 & 2014 & 2015 \\
\hline American Indian or Alaska Native & N/A & 2 & 2 \\
\hline Asian & N/A & 35 & 42 \\
\hline Black or African American & N/A & 15 & 18 \\
\hline Hispanic or Latino & N/A & 70 & 67 \\
\hline Native Hawaiian or Other Pacific Island & N/A & 2 & 0 \\
\hline Other Race/Ethnicity & N/A & 4 & 12 \\
\hline Prefer not to respond & N/A & 114 & 61 \\
\hline White & $\mathrm{N} / \mathrm{A}$ & 249 & 258 \\
\hline
\end{tabular}

Table 4. Summary of participant data over that past few years for the AFRL Scholars Program at Kirtland Air Force Base.

\begin{tabular}{|l|c|c|c|}
\hline & 2013 & 2014 & 2015 \\
\hline Participants & 111 & 123 & 127 \\
\hline New Mentors & 25 & 28 & 26 \\
\hline Returning Mentors & 54 & 56 & 66 \\
\hline Returning Scholars & 33 & 35 & 46 \\
\hline States Represented & 27 & 34 & 34 \\
\hline Males & 89 & 95 & 105 \\
\hline Females Ethnicity & 22 & 28 & 22 \\
\hline Academic Institutions Represented & 83 & 123 & 127 \\
\hline \hline & 2013 & 2014 & 2015 \\
\hline American Indian or Alaska Native & -- & -- & 1 \\
\hline Asian & 8 & 4 & 6 \\
\hline Black or African American & 2 & 3 & 2 \\
\hline Hispanic or Latino & 10 & 18 & 17 \\
\hline Multiple Race/Ethnicity & 6 & -- & -- \\
\hline Native Hawaiian or Other Pacific Island & -- & -- & -- \\
\hline Other Race/Ethnicity & -- & 2 & 4 \\
\hline Prefer not to respond/Unknown & 4 & 30 & 27 \\
\hline White & 81 & 66 & 70 \\
\hline
\end{tabular}




\begin{tabular}{|c|c|c|c|}
\hline Academic Level by Subprogram & 2013 & 2014 & 2015 \\
\hline High School/Phillips & 9 & 7 & 3 \\
\hline Freshman/Phillips & 8 & 2 & 2 \\
\hline Sophomore/Phillips & 9 & 4 & 5 \\
\hline Junior/Phillips & 11 & 12 & 18 \\
\hline Senior/Phillips & 13 & 26 & 28 \\
\hline \multicolumn{4}{|l|}{ Master's } \\
\hline Directed Energy & 6 & 5 & 7 \\
\hline Space & 31 & 28 & 23 \\
\hline \multicolumn{4}{|l|}{ Ph.D. } \\
\hline Directed Energy & 7 & 12 & 9 \\
\hline Space & 17 & 27 & 32 \\
\hline Academic Majors & 2013 & 2014 & 2015 \\
\hline Aerospace/Astronautical Engineering & -- & 28 & 32 \\
\hline Architecture & -- & 0 & 1 \\
\hline Astrophysics & -- & 4 & 1 \\
\hline Biomedical Engineering & -- & 0 & 1 \\
\hline Chemistry/Chemical Engineering & -- & 9 & 4 \\
\hline Civil Engineering & -- & 0 & 1 \\
\hline Computer Engineering/Programming/Science & -- & 5 & 6 \\
\hline Electrical Engineering & -- & 17 & 20 \\
\hline Geoscience & -- & 3 & 3 \\
\hline Interdisciplinary & -- & 0 & 1 \\
\hline Materials Science and Engineering & -- & 3 & 1 \\
\hline Mathematics & -- & 1 & 3 \\
\hline Mechanical Engineering & -- & 26 & 19 \\
\hline Nuclear Engineering & -- & 2 & 1 \\
\hline Optics & -- & 3 & 3 \\
\hline Physics/Engineering Physics & -- & 13 & 25 \\
\hline Undecided & -- & 7 & 5 \\
\hline
\end{tabular}

\section{OVERVIEW OF TWO OPTICS AND PHOTONICS RELATED INTERNSHIPS}

This section provides an overview of two optics and photonics related internships at the graduate and undergraduate levels, respectively, for the 2015 AFRL Scholars Program at Kirtland AFB in the Directed Energy Directorate. Both of the Scholars who participated on these projects were mentored by the lead author of this paper. With that said, both interns received the Outstanding AFRL Scholar Award in their respective categories. The selection process for these awards was highly competitive and was based on the review of a letter of recommendation from their mentor by an independent review panel. At the time of the awards, both of the Scholars had accepted abstracts for the upcoming 2015 Directed Energy Professional Society Systems Symposium in Norfolk, Virginia. Upon the completion of their internships, AFRL sponsored their travel to this conference, so that they could present their novel research at a larger forum outside of AFRL. Attendance at this conference ultimately served as a capstone experience.

Before moving on in the analysis, it is important to note that both interns are currently pursuing careers in optics and photonics. For example, the graduate Directed Energy Scholar went on to finish his MS degree in electro optics at New 
Mexico State University in the Klipsch School of Electrical and Computer Engineering. He then started a new job at the Army Research Laboratory, where he continues to work on defense-related projects which directly use optics and photonics. Similarly, the undergraduate Phillips Scholar went on to finish her BS degree in mechanical engineering at The Ohio State University in the Department of Mechanical and Aerospace Engineering. She then returned the following year for a second internship and will follow on to graduate school at the Air Force Institute of Technology to pursue her MS and PhD degrees in Optical Sciences and Engineering in the Department of Engineering Physics. Her graduate education is being funded by a Science, Mathematics, and Research for Transformation (SMART) Scholarship - more information can be found at https://smart.asee.org/. Since the Directed Energy Directorate is her sponsoring facility, her SMART Scholarship will ensure her employment at AFRL upon graduation. Overall, both internships really speak to the continued success of the AFRL Scholars Program, especially at Kirtland AFB in the Directed Energy Directorate.

\subsection{Digital holography wave-front sensing in the presence of atmospheric turbulence: a graduate-level internship}

With the use of modern digital holography methods, it is possible to detect the aberrations caused by atmospheric turbulence $[2,3]$. This detection process is commonly referred to as wave-front sensing. Over the summer, laboratory experiments were performed using digital holography wave-front sensing, as shown in Figs. 6-8. Mid-term and final presentations were prepared to both introduce and explain digital holography wave-front sensing to AFRL employees. In both presentations and a final report, an overview was given for the optical system design constructed in the laboratory to perform the digital holography wave-front sensing experiments. All experimental results were processed and analyzed using Lockheed Martin Coherent Technologies software. Several laboratory demonstrations were also discussed to confirm that the simulated atmospheric turbulence was accurate within the analysis.
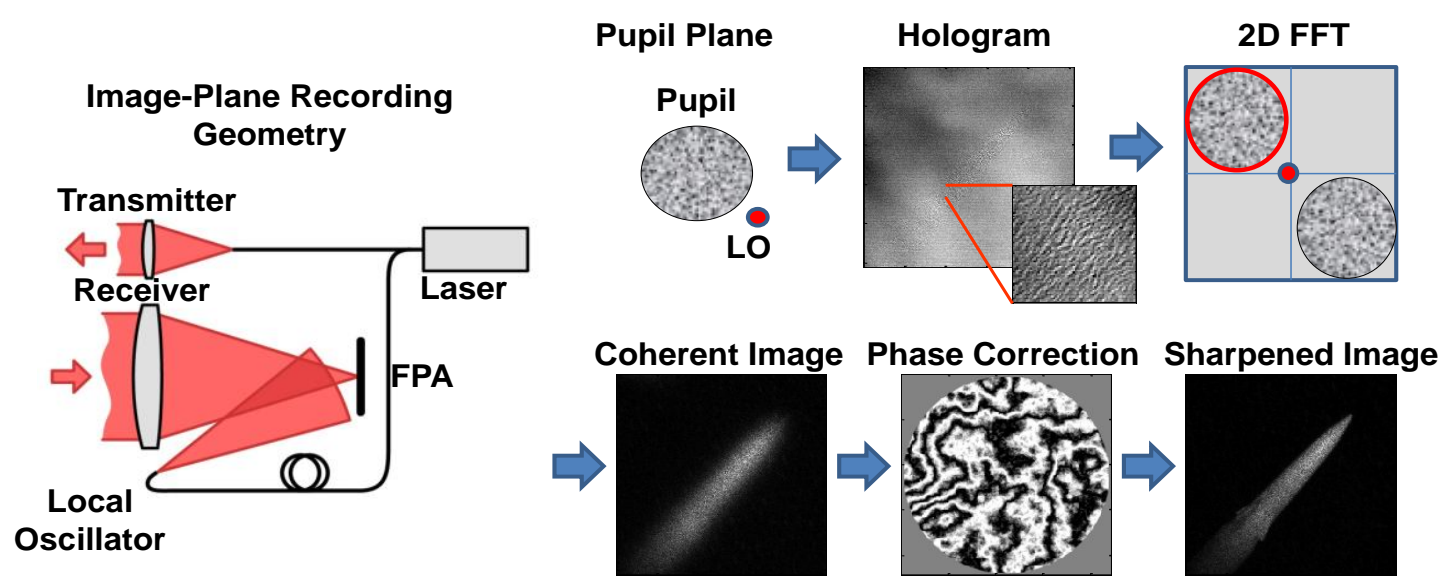

Figure 6. Digital holography (DH) is an optical process where coherent light is interfered with an off-axis reference beam, and the resulting hologram is recorded on a CCD camera or a similar detector. Upon taking the digital Fourier transform, these digital holograms contain complex-valued data, which can be used to perform wave-front sensing. Image sharpening also allows for user-defined areas of high-resolution-wave-front sensing.

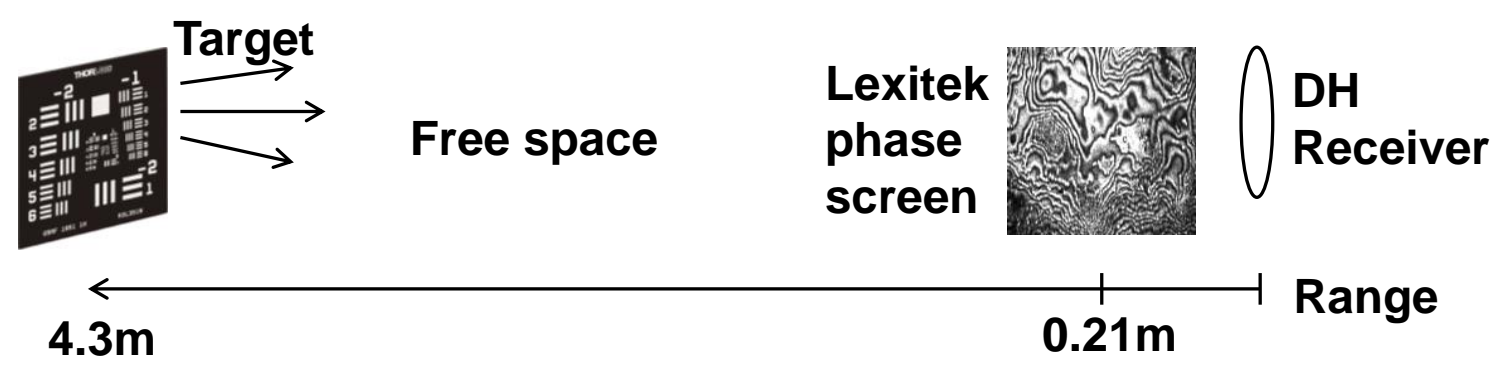

Figure 7. The nominal experimental setup. A highly coherent 532nm laser was used within the experiments. The reflected signal propagates though turbulent atmosphere, which was simulated using a Lexitek variable phase screen, to the

"Receiver" aperture which images the target onto the CCD camera. 


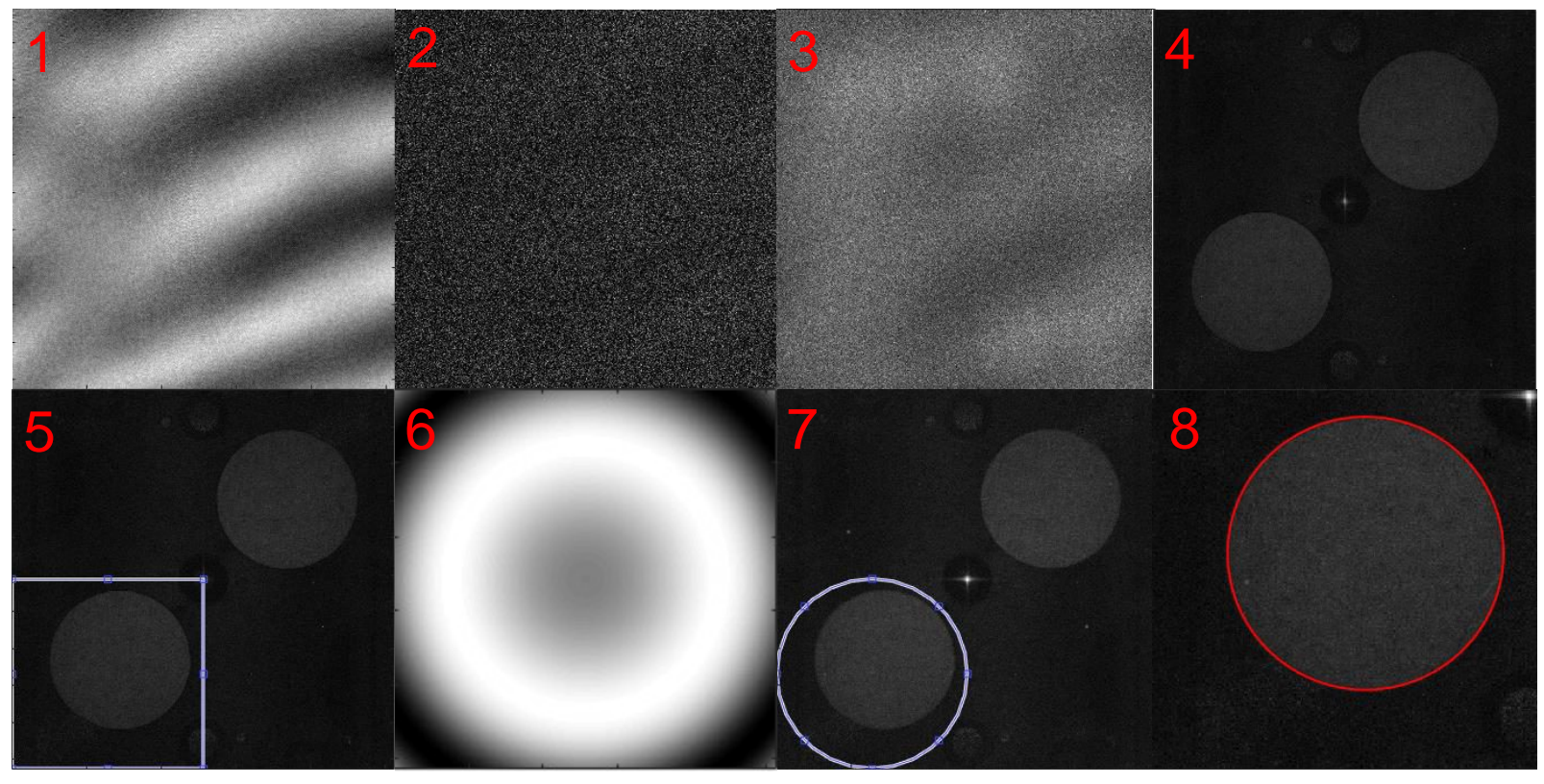

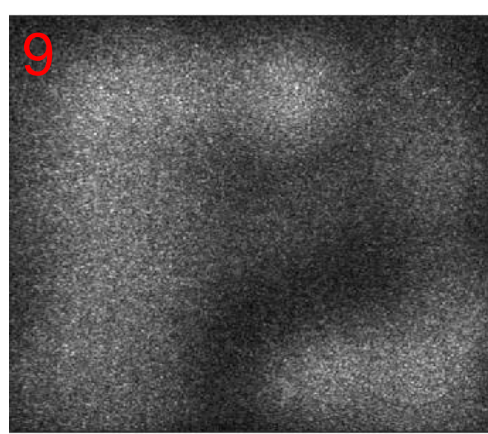

Original image

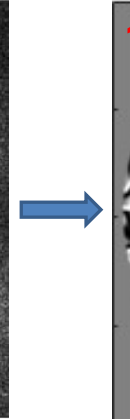

Estimated phase

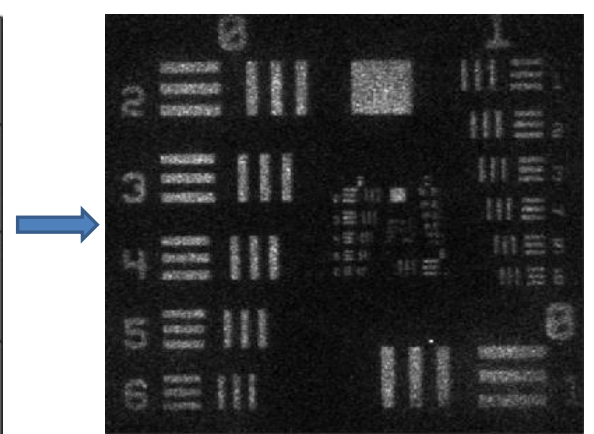

Sharpened image

Figure 8. Shown here is a pictographic representation of the sequence steps which were used to process the collected data to achieve a sharpened image from the original image by estimating the phase aberrations.

\subsection{Phased Beam Projection from Tiled Apertures: an undergraduate-level internship}

Phased beam projection from tiled apertures allows for $\mathrm{N}^{2}$ peak power scaling in the target plane without the need for logistically burdensome chemical lasers [4-6], as shown in Figs. 9-11. Instead, an N number of electronic lasers are spatially distributed at the source and are coherently combined into one powerful beam at the target. In general, the presence of phase aberrations results in lowered beam quality and reduces power in the bucket at the target. For the studies performed here, the analysis was simplified by grouping all parameters which degrade beam quality into a single phase screen which exists in the exit pupil of the tiled-aperture setup of interest. Experimental and simulation data show that macroscale phase aberrations negatively affect the performance of coherent beam combination when the correlation length of the phase screen is less than a subaperture radius. However, when the correlation length increases beyond a subaperture radius, performance stagnates at the coherent limit of about $80 \%$ of power in the coherent bucket for the seven subaperture case. Applying phase screens individually to each beamlet stagnates performance at $40 \%$ of power in the coherent bucket, regardless of phase screen correlation length. Over the summer, mid-term and final presentations were prepared to both introduce and explain these results to AFRL employees. A final report was also prepared. 

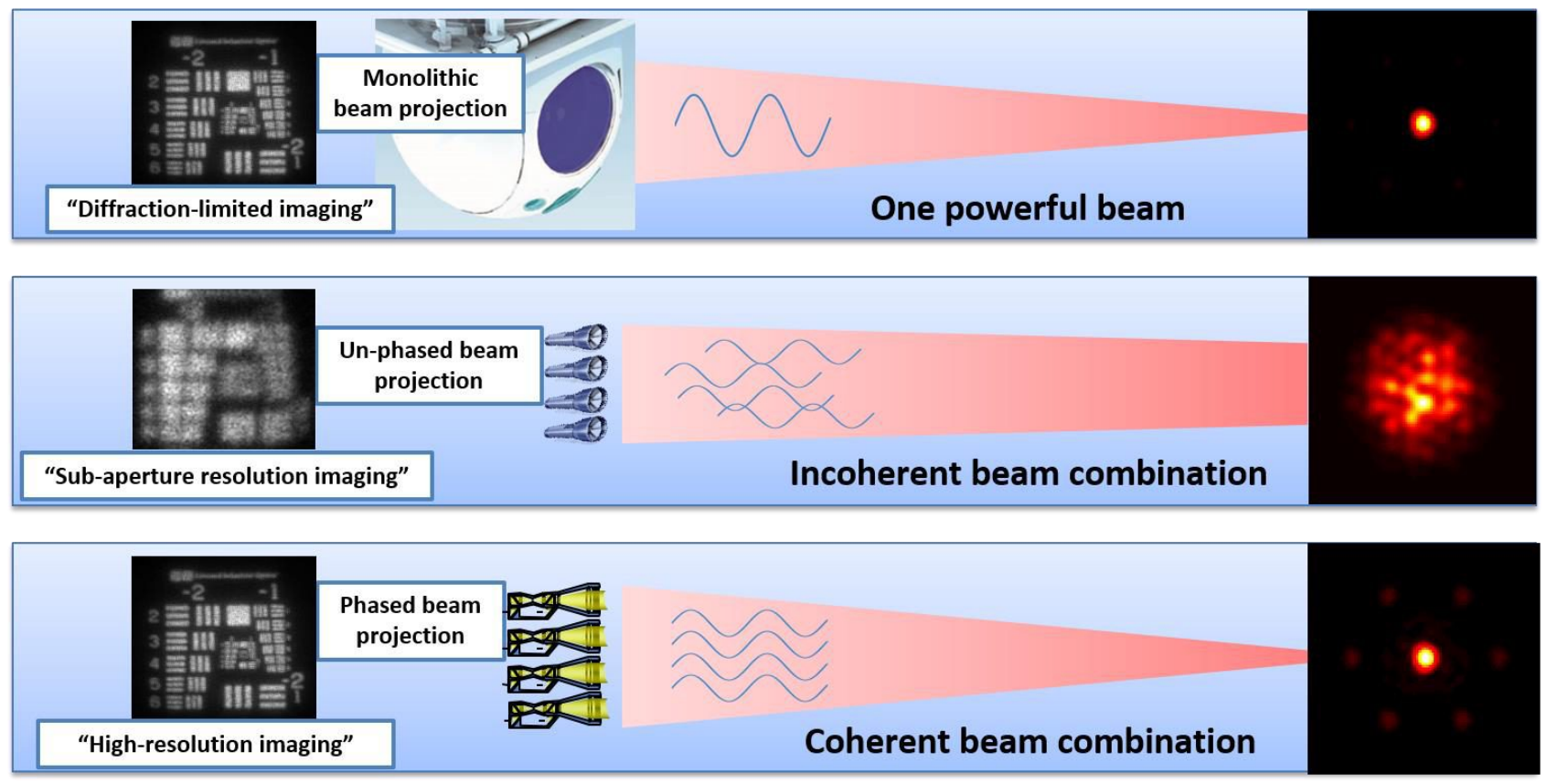

Figure 9. As the Air Force moves away from logistically burdensome yet powerful chemical lasers, it is important to find ways to consider less powerful yet more stable solid-state lasers. One of these concerns is scalability-it is required that these new systems have output powers of $150 \mathrm{~kW}$ or more. However, the output powers from solid-state lasers are limited to the single-digit $\mathrm{kW}$ range (because of bulk material considerations). Thus, it is necessary to combine the outputs of an $\mathrm{N}$ number of beamlets in order to reach this scaling requirement. Phased beam projection from tiled apertures allows for $\mathrm{N}^{2}$ peak power scaling at the target, and in turn, this allows the scalability requirements to be met under perfect conditions. However, phase aberrations degrade beam quality and lower coherent beam combination efficiency at the target. In this internship, all phase aberrations were reduced to a single Gaussian Schell Model (GSM) phase screen such that degraded beam quality could be simulated, as shown in Fig. 10.
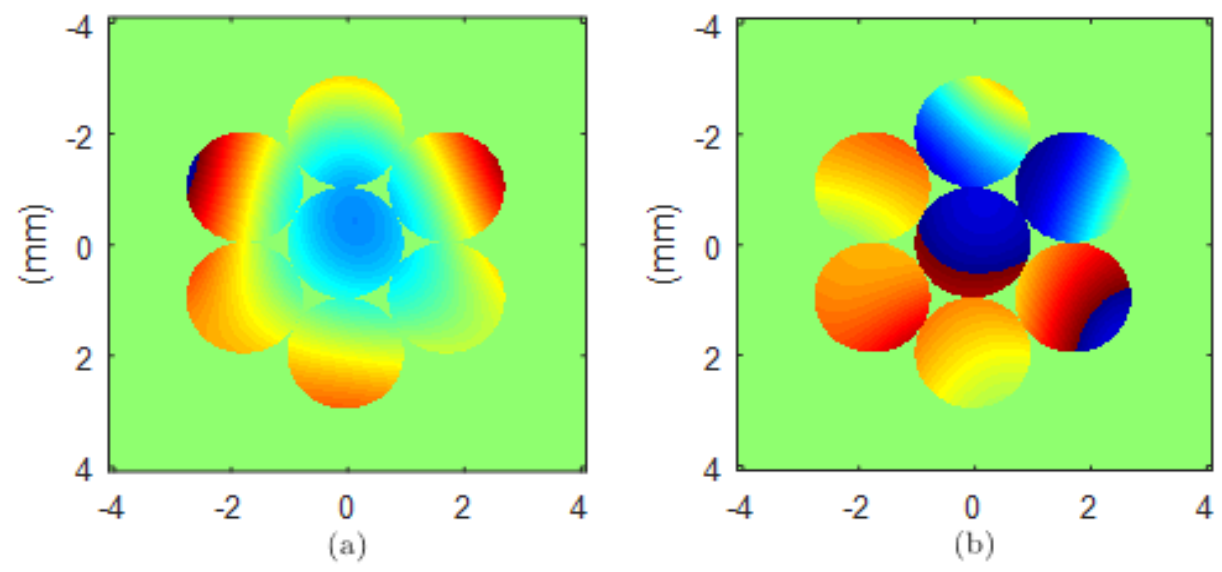

Figure 10. Two cases were investigated; in Case (a), a single phase screen affected all apertures, and in Case (b), each subaperture was affected by a different phase screen. These cases represent both macroscale and microscale effects, respectively. It was found that, for Case (a), power in the bucket increased linearly with increasing phase screen correlation length until the coherent limit was reached. For Case (b), phase screen correlation length did not affect target-plane performance. 


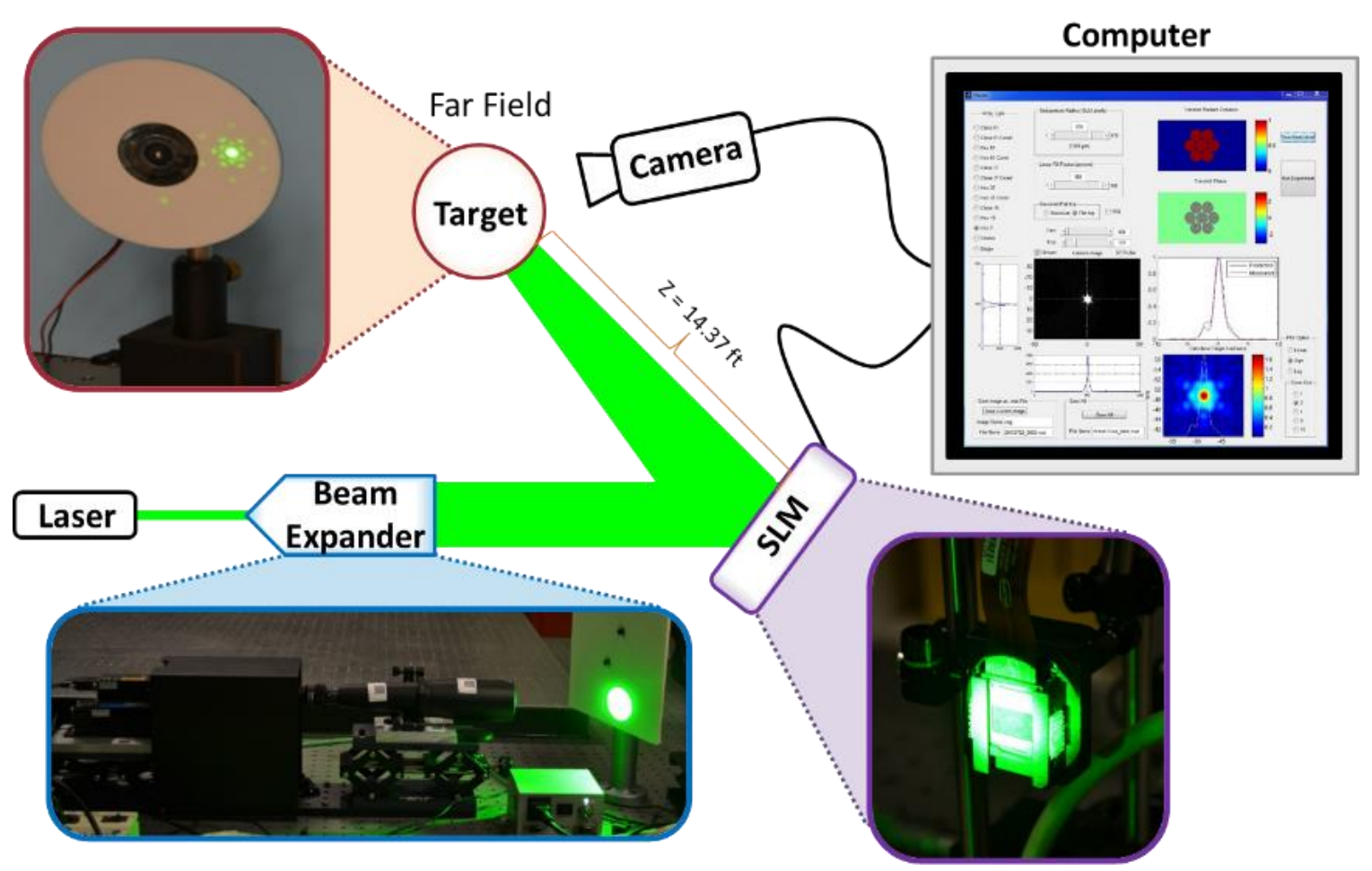

Figure 11. This study used computer wave-optics simulations to propagate a phased beam degraded by a GSM phase screen to the target plane for 500 iterations of Cases (a) and (b), such that Monte Carlo analysis was used. To ensure validity of the numerical simulations, experimental results were obtained in the AFRL/RDLTS Phasor Laboratory for the seven subaperture case. A diagram of the experimental setup is included above. A solid-state laser operating in the green $(\lambda=532$ $\mathrm{nm}$ ) was expanded to overfill the aperture of the spatial light modulator (SLM), providing essentially flat-top illumination. At the SLM, which allowed for experimental command of different tiled aperture geometries upon reflection, a new, randomly-generated phase screen was created for each iteration. Here, a lens phase was also applied such that the individual beams would focus to the same spot on the target. After reflection off of the SLM, the laser light propagated 14.37 feet to the target in the far field. For the target, a diffuse white paper-covered DVD was used and was mounted to a small motor. During experimentation, the DVD spun such that speckle averaging occurred with respect to the integration time of the CCD camera. Good agreement for propagation without aberrations was achieved between the analytical, simulated and experimental results.

\section{CONCLUSION}

The AFRL Scholars Program is a highly effective summer internship program that provides hands-on opportunities to students pursuing STEM-related career fields. Motivated students with top academic credentials in science and engineering fields are encouraged to visit the website to view the available research topics, contact the mentors, and to apply. Interested students may find out more information about this program by visiting the AFRL Scholars website: https:Ilafrlscholars.usra.edu, or email questions to: afrl.rvrd.1@us.af.mil.

\section{REFERENCES}

[1] Spencer, M. F., Steinbock, M. J., Hyde IV, M. W., and Marciniak, M. A., "The Laser Propagation Demonstration: a STEM-based outreach project," Proc. SPIE 9188 (2014)

[2] Spencer, M. F., Dragulin, I. V., Cargill, D. S., and Steinbock, M. J., "Digital Holography wave-front sensing in the presence of strong atmospheric turbulence and thermal blooming," Proc. SPIE 9617 (2015).

[3] Spencer, M. F., Raynor, R. A., Rhoadarmer, T. A., and Marker, D. K., "Deep-Turbulence Simulation in a ScaledLaboratory Environment Using Five Phase-Only Spatial Light Modulators," Proc. 18th Coherent Laser Radar Conference (2016). 
[4] Spencer, M. F. and Hyde IV, M. W., "An investigation of stairmode in optical phased arrays using tiled apertures," Proc. SPIE 8520 (2012).

[5] Spencer, M. F. and Hyde IV, M. W., "Phased beam projection from tiled apertures in the presence of turbulence and thermal blooming," Proc. SPIE 8877 (2013).

[6] Spencer, M. F., Thornton, D. E., Hyde IV, M. W., and Bos, J., "Piston Phase Compensation of Tiled Apertures in the Presence of Turbulence and Thermal Blooming," Proc. IEEE (2014). 